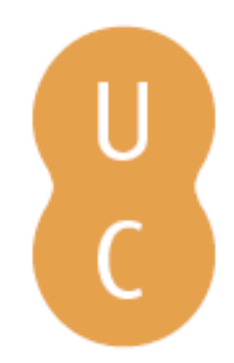

\title{
Rompalina
}

\section{Estudantes adultos no ensino superior: contextos e desafios}
Autor(es):
Ferreira, Ana Margarida Pinto
Publicado por: Imprensa da Universidade de Coimbra
URL persistente:
URI:http://hdl.handle.net/10316.2/31280
DOI:
DOI:http://dx.doi.org/10.14195/978-989-26-0228-8_17
Accessed : $\quad$ 26-Apr-2023 14:45:06

A navegação consulta e descarregamento dos títulos inseridos nas Bibliotecas Digitais UC Digitalis, UC Pombalina e UC Impactum, pressupõem a aceitação plena e sem reservas dos Termos e Condições de Uso destas Bibliotecas Digitais, disponíveis em https://digitalis.uc.pt/pt-pt/termos.

Conforme exposto nos referidos Termos e Condições de Uso, o descarregamento de títulos de acesso restrito requer uma licença válida de autorização devendo o utilizador aceder ao(s) documento(s) a partir de um endereço de IP da instituição detentora da supramencionada licença.

Ao utilizador é apenas permitido o descarregamento para uso pessoal, pelo que o emprego do(s) título(s) descarregado(s) para outro fim, designadamente comercial, carece de autorização do respetivo autor ou editor da obra.

Na medida em que todas as obras da UC Digitalis se encontram protegidas pelo Código do Direito de Autor e Direitos Conexos e demais legislação aplicável, toda a cópia, parcial ou total, deste documento, nos casos em que é legalmente admitida, deverá conter ou fazer-se acompanhar por este aviso.

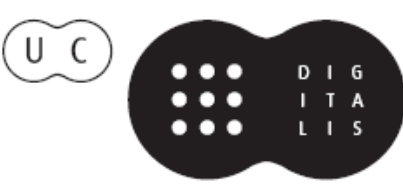




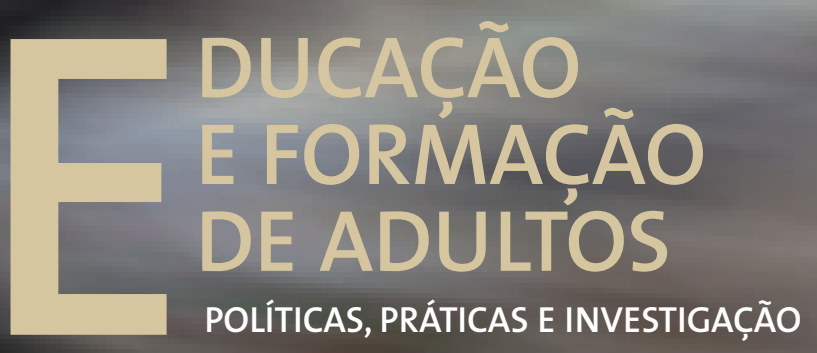

Luís Alcoforado • Joaquim Armando G. Ferreira António Gomes Ferreira • Margarida Pedroso de Lima Cristina Vieira • Albertina L. Oliveira • Sónia Mairos Ferreira 


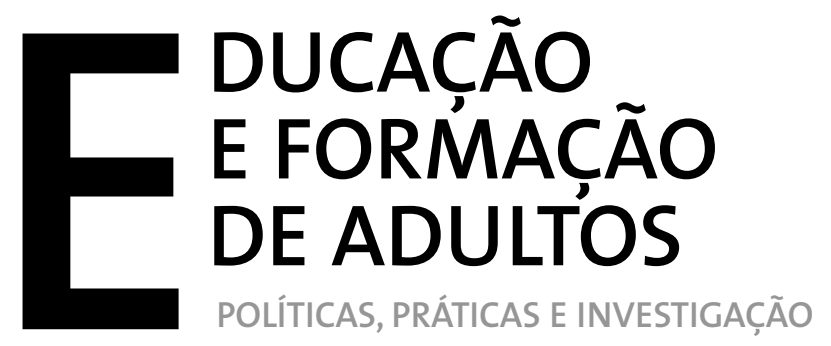

Luís Alcoforado • Joaquim Armando G. Ferreira António Gomes Ferreira - Margarida Pedroso de Lima Cristina Vieira • Albertina L. Oliveira • Sónia Mairos Ferreira 
EDIÇÃo

Imprensa da Universidade de Coimbra

URL: http://www.uc.pt/imprensa_uc

Vendas online: http://www.livrariadaimprensa.com

CONCEPÇÃO GRÁFICA

António Barros

Pré-Impressáo

SerSilito-Empresa Gráfica, Lda

EXECUÇÃo GRÁFICA

SerSilito-Empresa Gráfica, Lda

ISBN

978-989-26-0136-6

DePósito LEgaL

$340309 / 12$ 



\title{
Estudantes adultos no Ensino Superior: CONTEXTOS E DESAFIOS
}

\author{
Ana Margarida Pinto Ferreira \\ Instituto Politécnico de Setúbal
}

A transformação do que era um sistema de ensino superior de elites para um de massas é um movimento inegável na grande maioria de países desenvolvidos no final do século passado, sendo que a Organização para a Cooperação e Desenvolvimento Económico - OCDE - ou a Organização das Nações Unidas para a Educação, Ciência e Cultura UNESCO - reconhecem que essa metamorfose tem tido um impacto significativo na própria natureza deste nível de ensino quer em termos da sua estrutura, finalidade ou papel social e económico (OCDE, 1998, UNESCO, 1998 citados por Schuetze \& Slowey, 2002). Num ensino superior que se encontrava até há alguns anos restringido a um pequeno grupo da população (em termos de idade, classe social, origem e até de género) uma das mais significativas facetas daquela transformação reflecte-se ao nível do número e tipologia dos estudantes que acedem ao ensino universitário e politécnico presentes, tal como adiante analisado, quer por vias de entrada alternativas, onde sujeitos com diferentes escolaridades se incluem, como pelo alargamento do papel das próprias instituiçóes de ensino superior de formar ao longo de toda a vida, fazendo simultaneamente com que os indivíduos vão sentindo perdurar a necessidade de recurso ao sistema educativo. Efectivamente, parte do processo de expansão e heterogenia reflecte-se na participaçáo em número crescente de novos grupos de estudantes onde os adultos em especial representam um número significativo.

Uma análise um pouco mais profunda destas alteraçóes traz à superfície a inegável constatação de que proporcionar simplesmente a entrada de novos públicos no ensino superior não garante uma verdadeira igualdade de oportunidades e vários autores - Canário (2004), Knapper e Cropley (1991, 2000), Mark (2006), Pires (2008; 2009) UNESCO (2009), citando apenas alguns exemplos - parecem ser unânimes em retratar o modo a ir ao encontro das necessidades de um grupo de estudantes cada vez mais diverso e diversificado como um desafio futuro para as instituiçóes.

Estas questóes moldam um projecto realizado ao longo do ano de 2010 (Ferreira, 2010) e que teve por objectivo central a apresentaçáo de linhas para o desenvolvimento do apoio aos estudantes e candidatos adultos numa dada instituição de ensino superior portuguesa. Tendo em conta não apenas a pesquisa subjacente mas também a recolha de contributos realizada, o que se apresenta nas linhas seguintes será não tanto o projecto em si, direccionado a uma instituição específica, mas as grandes conclusóes de um ponto de vista geral e que poderão representar um contributo para as instituiçóes de ensino superior portuguesas de um modo abrangente.

$\mathrm{O}$ contexto em que se inserem, quem são e os desafios que representam os estudantes adultos são as bases de uma análise que pretende sugerir acçóes a tomar por parte das instituiçóes em termos de intervenção na área da Educação de Adultos no ensino superior. 


\section{Os Contextos}

\section{Transformaçöes no Ensino Superior}

Centrando o nível de análise no contexto europeu e especificamente em Portugal, recentemente o sistema de ensino superior nacional foi alvo de um processo de reforma já que o país se inclui no grupo dos signatários da Declaração de Bolonha em 1999. As reformas decorrentes deste processo tiveram por objectivo um esforço de renovação e de uniformização do ensino superior ao nível da União Europeia - UE - "visando a consolidação do espaço europeu do ensino superior e a completa integraçáo e aceitação internacional dos diplomados" (Eurydice, 2007, p. 275). O Processo de Bolonha representará uma oportunidade para incentivar a frequência do ensino superior, para melhorar a qualidade e a relevância das formaçóes oferecidas e para fomentar a mobilidade e a internacionalização dos estudantes (idem, ibidem) o que se traduz, em termos muito práticos, em itens como um novo modelo de organização do ensino superior no que respeita aos três ciclos de estudos, o estabelecimento de um sistema coerente e comparável de créditos com o European Credit Transfer System ECTS -, o enfoque nos resultados da formação (os learning outcomes e as competências) e o consequente incentivo a novas abordagens educativas e a possibilidade do reconhecimento formal das aprendizagens adquiridas fora do sistema educativo, entre outros.

Por outro lado, as profundas reformas legislativas operadas tiveram impacto no próprio sistema de acesso a este nível de ensino. Efectivamente, fez-se sentir uma muito maior abertura à entrada de novos grupos de estudantes, entre os quais indivíduos que não possuíam as tradicionais habilitaçóes exigidas e que estavam fora dos limites etários convencionais. Esta possibilidade não representa propriamente uma novidade tendo em conta que essa oportunidade já antes existia; no entanto o que se verifica é uma verdadeira democratização do acesso ao ensino superior, com claro investimento não só legislativo como também das próprias instituiçóes, e que obtém resultados muito significativos. Com o Decreto-Lei n. ${ }^{\circ}$ 64/2006 e subsequente implementaçáo das provas especialmente adequadas destinadas a avaliar a capacidade para frequência do ensino superior por maiores de 23 anos - concurso Maiores de 23 anos - é reformulada a via de acesso destinada aos adultos (antigo exame $\mathrm{Ad}$-Hoc), sendo que para a avaliação dos candidatos passa a ser relevante náo só a sua prestaçáo em provas da responsabilidade de cada instituição de ensino superior, mas também a apreciação do seu currículo escolar e profissional assim como das suas motivaçóes para o ingresso. $\mathrm{O}$ próprio concurso geral de acesso contempla agora novos meios de entrada para cidadãos cuja habilitação de nível secundário é proveniente de iniciativas onde não obtêm a classificação final desse nível de ensino, através da realização exames nacionais do ensino secundário que se constituem como provas de ingresso para o par estabelecimento/ curso a que pretendem aceder - Deliberação n. ${ }^{\circ}$ 1650/2008, de 13 de Junho, da Comissão Nacional de Acesso ao Ensino Superior. Também o concurso especial para titulares de cursos superiores, póssecundários e médios, previsto no Decreto-Lei no 393-B/99, ganhou nova amplitude com a regulamentação ao nível dos Cursos de Especialização Tecnológica (CET) - Decreto-Lei n. ${ }^{\circ} 88 / 2006$ - permitindo assim uma maior abertura a mais um segmento da população.

É porém inegável que todas estas transformaçôes se relacionam primordialmente com uma imposição legislativa e não com um movimento natural de evolução do sistema de ensino superior. 


\section{Cultura do Ensino Superior}

A pesquisa e investigaçáo são geralmente consideradas como as actividades centrais na educação de nível superior; este facto implica que o ensino superior seja muito marcado por uma tradição académica e de pesquisa, associada a uma cultura tradicionalista e algo fechada à mudança no que à aceitação de novas práticas diz respeito. Em 2007, no capítulo em que analisa os programas educacionais, o relatório da OCDE sobre o sistema educativo terciário português refere que a maior parte das instituiçóes públicas aparentam não ter entendido nem incorporado a transformação para um ensino superior de massas e a responsabilidade que têm em responder à diversidade e necessidades dos cada vez mais diferenciados estudantes, recusando aceitar o seu papel no sucesso daqueles que admitem (OECD, 2007). No âmbito da audição "Novas Oportunidades para Novos Públicos no Ensino Superior", inserida no Debate Nacional sobre Educação, é traçado um quadro que vai de encontro ao que se acaba de referir - a inércia e uma atitude tradicionalista parecem dominar as instituiçóes que se vêem confrontadas com a realidade cada vez mais presente da educação e formação de pessoas adultas: "as instituiçóes não têm sido capazes de vencer a inércia e reorientar a sua missão. Para além das dificuldades inerentes à mudança em instituiçóes (...) Reconhece-se a existência de constrangimentos culturais, dos agentes de Ensino Superior e do espírito das próprias instituiçóes” (Silva, 2007, p. 122).

Por outro lado, não será errado reconhecer que todas as transformaçóes legislativas reflectem a introdução (ou a tentativa) de princípios da Aprendizagem ao Longo da Vida - ALV - no nível de ensino superior (patente nas novas modalidades de entrada, na maior atenção aos resultados, às competências a adquirir, à importância do reconhecimento dos adquiridos...). No entanto, mesmo neste aspecto, o relatório de um estudo feito pela European University Association - EUA - em 2003 (cit. por Mark 2006) refere que, ao nível europeu, a ALV é marginalizada pela grande maioria das instituiçóes e raramente integrada na estratégia, processos nucleares e nas tomadas de decisão, sendo ainda salientado que poucas ou nenhumas alteraçóes se verificaram ao nível do ensino. Outros autores suportam estes factos. Schuetze \& Slowey (2002), num estudo em que são descritas e analisadas as políticas públicas e institucionais e os desenvolvimentos recentes em termos de ALV em 10 países (entre os quais Alemanha, Áustria, Irlanda, Reino Unido ou Suécia), reportam que na generalidade dos países, senáo em todos, apesar da vincada onda expansionista, as instituiçóes de ensino superior (em particular as universidades) aparentam não terem abraçado substancialmente a ALV como missão nuclear. Osborne (2003 cit. in Mark, 2006) argumenta que muitas das mudanças em desenvolvimento ao nível europeu são dirigidas para a acção e não reflectem um compromisso genuíno com a obtenção de maior equidade, podendo ser encaradas unicamente como respostas de curto-prazo a exigências dos próprios grupos tradicionais.

Assim, o que acaba por se verificar é que, apesar de todas as transformações ocorridas, a cultura vivida no ensino superior tem mostrado algumas dificuldades na abertura a um verdadeiro compromisso com a ALV; as instituiçóes continuam na sua grande maioria muito direccionadas para um tipo específico de estudante, pensado numa perspectiva algo tradicional. No estudo "O ensino superior aberto a novos públicos" publicado em 2002 (Santiago, Rosa \& Amaral, 2002) já era retratada a tendência das instituiçóes de ensino superior para direccionarem o foco para os estudantes adultos, perspectivando o conformismo destes ao instituído, e não tanto para si próprias e para a sua necessidade de 
mudança e adaptação tendo em conta o peso dos cada vez mais numerosos alunos adultos. Num registo mais recente Lourtie (2007, p. 109) salienta também este mecanismo afirmando que "a realidade é que estes públicos eram, ou são ainda, enquadrados em percursos escolares pensados para jovens vindos directamente do ensino secundário e que não têm em consideração as suas características e necessidades específicas”.

\section{Os Estudantes Adultos no Ensino Superior}

Pensarmos nos estudantes adultos tendo em conta apenas o critério idade ou definindo-o como o grupo de estudantes que acede ao ensino superior através dos concursos Maiores de 23 é extremamente redutor e leva-nos a uma percepção limitada de quem são estes estudantes, das suas características, das suas especificidades e até das suas necessidades dentro do sistema. É inegavelmente necessária a identificação do grupo em causa ao considerarmos as questóes da participação.

No período de educação superior elitista, prévio à massificação deste nível de ensino, os estudantes adultos eram a minoria, quase sempre definidos por oposição ao estudante dito "tradicional"; a fronteira era tendencialmente traçada ao redor de todos aqueles que não tinham entrado directamente do ensino secundário, não estudavam a tempo inteiro ou exerciam outra actividade como principal ocupação, e não pertenciam ao grupo social dominante (Schuetze \& Slowey, 2002). Na América do Norte, a partir dos anos 70, as instituiçóes de ensino superior começaram a sentir a entrada significativa de alunos a quem o termo "estudantes não tradicionais" foi aplicado; as diferenças mais significativas evidenciavam que estes estudantes eram mais velhos e tinham interrompido a educação formal tanto depois como antes de acabarem o ensino secundário. Progressivamente as instituições de ensino pós-secundário de outros países desenvolvidos foram também sentindo esta evolução (Maeh, s.d.).

Schuetze \& Slowey (2002) identificam três critérios que aparentam ser nucleares para a definição de estudantes adultos ou não tradicionais: i. biografia educativa (os estádios biográficos que conduziram o indivíduo ao ensino superior e as variaçóes ao nível da motivação para o estudo ao longo do ciclo de vida da pessoa); ii. percursos de entrada (modo como é feito o acesso ao ensino superior e a altura em que tal acontece); iii. modo de estudo (os padróes e intensidade da frequência dos estudos e a interacçáo entre estes e outras actividades do sujeito - como trabalho, vida familiar, etc.). Lourtie (2007, p. 108), por sua vez, refere que "o que se convencionou chamar "novos públicos» do ensino superior são, no essencial, cidadãos que acedem ao ensino superior não tendo completado uma formação superior na juventude, não detendo as qualificaçóes formais de acesso ou pretendendo reconverter-se para outra área de conhecimento". Em conclusão, no que respeita à sua definição, o estudante adulto ou estudante não tradicional no ensino superior deve ser contemplado tendo em conta: i. idade cronológica, sendo que em termos etários ultrapassam a barreira dos meados dos 20 anos; ii. biografia educativa já que em termos de ensino formal geralmente interromperam os estudos sem obterem uma habilitação e/ ou retomam-nos depois de um período de interregno; e ainda iii. situaçáo profissional e familiar considerando que são ou já foram profissionalmente activos detendo, num número significativo de casos, responsabilidades ao nível familiar. 
Além de definir quem integra este grupo há que considerar, por exemplo, as dificuldades por que os estudantes adultos passam ao reintegrarem o ensino e que são também documentadas. No estudo ALPINE - Adults Learning and Participating in Higher Education -, terminado em 2004 e onde se incluiu a participaçáo de Portugal, conclui-se

que a integração dos adultos nas universidades europeias é influenciada por barreiras que Cross (1981 cit. por Mark, 2006) classificou em três categorias: i. pessoais - quando o individuo tem atitudes, percepçóes ou expectativas que afectam a sua capacidade ao nível da participação (como baixas aspiraçóes, baixa auto-estima, falta de hábitos de estudo ou experiências educativas negativas anteriores); ii. situacionais - relacionadas com a situação do sujeito (falta de tempo, distância da residência, falta de condiçôes para estudar ou ir às aulas, custos associados estudos); iii. institucionais - percepção por parte da instituição educativa como sendo um estabelecimento direccionado apenas a estudantes na sua vertente mais tradicional (isto é, não considerando a variabilidade); iv. e uma quarta acrescentada por McGivney (1991 cit. por idem, ibidem): as barreiras informativas que se prendem com as dificuldades que os estudantes adultos têm em aceder às informaçóes relevantes no âmbito educativo.

Adicionalmente, podem ser consideradas ainda características que, ao nível da participação propriamente dita, mais do que evidenciarem diferenças em relação aos colegas mais jovens, revelam traços de um possível padrão ou perfil comum nos estudantes adultos. Knapper e Cropley $(1991,2000)$ apontam especificidades nesta população estudantil como a abordagem algo divergente em relação aos colegas mais jovens que os adultos fazem ao processo de aprendizagem já que possuem preocupaçóes (emocionais, interpessoais, sociais, etc.) que não são geralmente consideradas como "académicas"; o facto de trazerem para a situação de aprendizagem objectivos pessoais claramente desenvolvidos, ideias mais claras e melhor formuladas daquilo que constitui para si uma matéria útil assim como o desejo de aprender coisas que eles próprios definem como relevantes já que muitas vezes têm uma aplicaçáo relativamente imediata em situaçôes da sua vida real; um possível padrão de desistências e reingressos nos cursos que é muitas vezes incompatível com a organização curricular geralmente disponibilizada; acrescentam ainda especificidades como a falta de predisposição um tratamento infantilizado no ambiente de aprendizagem, a sensibilidade a factores sociais (como o receio do ridículo), a sobrevalorização da escola e do ambiente formal de aprendizagem acompanhado pela desvalorizaçáo de aprendizagens feitas em ambientes não formais, entre outros.

No fundo, todos estes traços, factores, características, tornam óbvio que a frequência do ensino formal de nível superior por parte dos adultos será, tal como McGivney (1999 cit. in Mark, 2006, p. 38) refere, influenciada por uma multiplicidade de factores e resultado de um processo complexo: "adult participation is the result of a complex process. Is the interaction of a whole swathe of cultural, structural and pratical factors (...). An understanding of these should inform any approaches designed to increase their participation".

\section{Os Desafios}

De acordo com o exposto assiste-se, então, ao aumento significativo do grupo de estudantes adultos, com características próprias num sistema de ensino superior impelido para uma cada vez maior abertura e inclusão de novos públicos mas que demonstra dificuldades 
em sair da sua perspectiva algo tradicionalista sendo que as mudanças que se fazem sentir são, no essencial, restritas ao nível do acesso.

A verdade é que a necessidade de encontrar vias alternativas para que os adultos participem nas oportunidades de aprendizagem disponibilizadas no ensino superior é amplamente reconhecida. Para que o alargamento da participação seja bem sucedido é necessário dar-lhe prioridade elevada em termos de mobilizaçáo de uma cultura institucional de suporte e um verdadeiro compromisso para incluir grupos não tradicionais (idem, ibidem), factores sem os quais poucas possibilidades existirão de êxito não só na inclusão como no percurso dos estudantes adultos. Tal como Pires (2008, p. 2) refere:

\begin{abstract}
"No actual contexto político-educativo, em que se incentiva a participação dos adultos no ensino superior, parece-nos fundamental reflectir não apenas sobre as questóes do acesso, mas também sobre as questóes do sucesso deste novo público-alvo. Desta forma, torna-se necessário analisar e desenvolver as condiçóes que garantam a continuidade e a evolução dos novos públicos no seio dos sistemas educativos. O alargamento do acesso e da participação dos adultos não se esgota com a implementação de novos mecanismos facilitadores da entrada: torna-se necessário criar condiçóes para a sua progressão e sucesso, o que vai depender da estrutura, da flexibilidade e da coerência (tanto pedagógica como organizacional) do próprio sistema".
\end{abstract}

As políticas governamentais influenciam a participação no ensino superior tanto quanto ao número de participantes como também (e principalmente) em quem são esses participantes; as políticas educacionais têm o potencial tanto de poderem elevar barreiras à participação como de alargar as oportunidades a um grupo mais abrangente de estudantes (Mark, 2006). Será exactamente aqui que estão os desafios que cada vez mais se impóem às instituiçôes.

Ganha assim relevância a questão de como podem as universidades e politécnicos evoluir mantendo contudo as suas potencialidades no campo da pesquisa, ensino e modelagem da democracia e responsabilidade social, especialmente no que aos estudantes adultos ou não tradicionais diz respeito. Especificamente no âmbito desta comunicação, o foco centra-se no modo como as instituiçôes podem incluir acçôes e estruturas que contemplem o apoio aos estudantes adultos de modo prático e realista. Tendo em conta a pesquisa efectuada na literatura nacional e internacional (Ferreira, 2010) passam a propor-se princípios que podem ser tidos em consideraçáo pela generalidade das instituiçóes num movimento de mudança e modernização; são apontadas algumas propostas organizadas em três níveis - o do ensino, o dos serviços e o institucional - assumindo um discurso de cariz eminentemente prático.

No âmbito do ensino é amplamente referida a importância da aprendizagem centrada no estudante perseguindo um cariz de teor individualizado tanto quanto possível. Deste modo, a implementação de processos sólidos de reconhecimento de adquiridos por parte das instituiçóes fornecerá aos estudantes a possibilidade de realizarem percursos alternativos de progressão académica; por outro lado a aprendizagem por projecto ou por resolução de problemas, a aprendizagem com pares, o recurso à auto-aprendizagem e o incentivo da reflexáo crítica deverão estar numa primeira linha dos recursos a utilizar por parte dos docentes. Um pouco dentro desta lógica, vários autores sugerem a generalizaçáo de posturas alternativas por parte daqueles últimos: o docente como mentor, como facilitador do processo de aprendizagem, como alguém que disponibiliza os seus recursos em termos 
de conhecimentos e técnicas para a realização de um trabalho em equipa com o estudante adulto, em que é favorecido o feedback contínuo. Também a reformulação modos e instrumentos de ensino e avaliação é referida, sugerindo-se uma maior flexibilidade em termos dos regimes de frequência presencial, a aposta nas Tecnologias de Informaçáo e Comunicação, no e-learning e b-learning, uma ligação próxima entre a aprendizagem e a realidade (contexto profissional, por exemplo) que assegura a relevância da experiência de aprendizagem para o adulto e em que o recurso a especialistas (docentes, profissionais) pode ser privilegiado; e a integração, tanto quanto possível, das diferentes disciplinas e matérias.

No que diz respeito aos serviços das instituiçôes, uma medida de inestimável valor pode passar por algo tão simples como a disponibilização de horários pós-laborais em todos os serviços utilizados pelos estudantes adultos, sejam eles os serviços académicos, os centros de documentação e bibliotecas, serviços de acção social, de acompanhamento psico-pedagógico, etc. Por outro lado, existem uma série de valências que devem ser disponibilizadas contemplando este grupo de estudantes; estes são serviços que existem já em algumas instituiçóes mas que estão espartilhados e/ou são muitas vezes direccionados para um perfil de estudante que não se adequa às características dos adultos. É aliás defendida por alguns autores a existência de um gabinete específico nas instituiçóes para o atendimento aos estudantes adultos, um serviço central com diversas valências assumindo-se como um ponto de referência para informaçáo e apoios dirigidos aos candidatos e estudantes adultos contemplando: i. informação acerca dos vários recursos disponíveis na comunidade académica de modo a facilitar o enquadramento e recurso num sistema que é para muitos estranho e desconhecido (serviços e suas funçóes, estratégias e actividades institucionais, vida académica, etc.); ii. apoio administrativo, pedagógico, serviços de aconselhamento e orientação pessoal e académicos pensados para este grupo de estudantes e para as suas questôes e dificuldades específicas; iii. disponibilização do processo de reconhecimento de adquiridos experienciais e respectivo apoio de modo a realizar um processo formativo e integrado no percurso académico frequentado; iv. workshops na entrada ou ao longo do percurso: revisão de competências em disciplinas básicas (matemática, escrita, etc.) assim como de competências académicas (pesquisa bibliográfica, redacção de trabalhos e relatórios, métodos de estudo, entre outros); v. programas de mentoring/grupos de apoio para estudantes adultos realizados por técnicos ou colegas adultos (facilitação da integração, partilha de experiências específicas, etc.); vi. formação dirigida à comunidade académica de modo a sensibilizar o pessoal docente e não docente para as características e especificidades desta população.

Em termos institucionais será importante um investimento na divulgação daqueles serviços e apoios através de informação clara e acessível a toda a comunidade académica assim como a mobilização contínua do pessoal docente que detém um papel central na implementaçâo das abordagens educativas. Aliás, qualquer iniciativa de apoio aos estudantes adultos (pedagógica, institucional, estudantil, etc.) deve ser reconhecida e valorizada institucionalmente perante a comunidade académica de modo a estimular e instituir essas práticas. Universidades e politécnicos devem realizar uma aposta clara no estabelecimento de cursos com frequência em part-time à semelhança do que é já amplamente praticado em países como os Estados Unidos da América que possuem uma longa tradição no acolhimento de adultos no ensino superior. Adicionalmente deve existir uma flexibilização da saída e reentrada no percurso académico, aligeirando prazos e aspectos burocráticos. Idealmente, estas iniciativas deverão estar ligadas a uma cada vez maior disponibilização 
de cursos regime nocturno ou pós-laboral ou, no mínimo, a uma maior amplitude nos horários dos cursos diurnos. As questóes ligadas aos estudantes adultos devem, no fundo, tomar cada vez mais a forma de algo inerente e fulcral nas políticas e cultura organizacional, assumindo-se o investimento e a discussão regular destas temáticas como um dos objectivos institucionais.

\section{Reflexóes Finais}

Existe uma necessidade clara de integrar as especificidades dos estudantes adultos nas políticas, processos de desenvolvimento e práticas das instituiçóes de ensino superior indo além da garantia de acesso. Estratégias coerentes e de cariz activo têm de ser desenvolvidas de forma a permitir que a Educaçáo de Adultos se torne uma realidade aberta e flexível neste nível de ensino, permitindo aos aprendentes escolher os seus próprios caminhos de aprendizagem, aqueles que servem acima de tudo os seus interesses e necessidades.

Não é expectável que as instituiçóes pura e simplesmente recomecem ou reiniciem o seu funcionamento de modo a incluírem em toda a amplitude os princípios necessários e ideais de uma organização voltada para a Educação e Formação de Adultos, até mesmo porque continuam a abranger outros públicos e a contemplar outras funçóes. Por outro lado, as mudanças aqui indicadas não compreenderão certamente a totalidade de iniciativas em que as instituiçóes de ensino superior podem investir no apoio aos seus estudantes mais velhos. No entanto afigura-se relevante avançar com linhas de desenvolvimento para o apoio e valorização destas novas e cada vez mais significativas populaçóes do ensino superior. $\mathrm{O}$ grande objectivo é o incentivo à reflexão, à revisão crítica de práticas instituídas em sistemas tradicionalmente fechados, à actuação na esfera institucional mas também ao nível particular e individual para que uma tão necessária renovação de ideologias e práticas aconteça efectivamente nas instituiçóes.

Cherqui-Houot (2001 cit. por Pires, 2009, p. 11), analisando a evolução dos sistemas de reconhecimento e validação de aprendizagens, avança três possíveis cenários para o ensino superior:

- "as instituições de E.S. podem escolher o evitamento, ignorando ou não fomentando o debate interno; limitando as novas práticas a experiências pontuais, a espaços circunscritos, a actores isolados, a experiências «farol»;

- podem ceder à tentaçáo de reproduzir os modelos sociais dominantes - a saber, o modelo «industrial» e o modelo do "mercado» -, apropriando-se de uma visão utilitária e estratégica do saber e do conhecimento, com vista à «industrializaçáo» e "comercialização» dos seus produtos; podendo assim acentuar a actual tendência actual do sistema educativo, «massificando» o acesso ao diploma por esta via;

- podem ainda aproveitar o debate que agora se relança reapropriando-se da sua função crítica (desocultando as lógicas e as tensóes subjacentes) e da sua missão formativa - procurando conciliar a formaçáo das pessoas enquanto dialéctica de processos e resultados, garantindo uma sólida formação científica, profissional e cultural”.

Estes cenários são generalizáveis ao panorama do apoio aos adultos neste sistema educativo; e será de todo desejável que o último seja aquele que se perspectiva no futuro 
de um ensino superior de qualidade, caracterizado pela conciliação da justiça social, pela preocupação com o aumento da participaçáo e da sua importância para a sociedade em geral (Ferreira, 2010).

\section{Referências Bibliográficas}

Canário, R. (2004). Formaçáo profissional: problemas e perspectivas de futuro. In L. Lima (org.), Educaçâa de Adultos - Fórum III (pp. 112-125). Braga: Unidade de Educação de Adultos - Universidade do Minho.

Eurydice (2007). Eurybase The Information Database on Education Systems in Europe - Organização do Sistema Educativo em Portugal 2006/07. Bruxelas: Eurydice. Acedido a 28 de Fevereiro de 2010 em: http://eacea. ec.europa.eu/education/eurydice/documents/eurybase/eurybase_full_reports/PT_PT.pdf

Ferreira, A. M. (2010). Educação e Formação de Adultos e Ensino Superior: linhas de desenvolvimento do apoio ao estudante adulto. Trabalho de Mestrado em Ciências da Educação não publicado. Lisboa: Instituto de Educação da Universidade de Lisboa.

Knapper, C. K. \& Cropley, A. J. (1991). Lifelong learning and higher education. London: Kogan Page.

Knapper, C. K. \& Cropley, A. J. (2000). Lifelong learning and higher education. London: Kogan Page.

Lourtie, P. (2007). Novos públicos e novas oportunidades de certificação: ensino superior. In P. Santos \& B. Campos (Coord.), Aprendizagem ao Longo da Vida no Debate Nacional sobre Educação (pp. 105-114). Lisboa: Conselho Nacional de Educação.

Maeh, W. (s.d.). Nontraditional Students in Higher Education. Acedido a 28/02/2010 em: http://www.answers. com/topici/nontraditional-students-in-higher-education

Mark, R. (2006). Increasing adult participation in higher education. In R. Mark, M. Pouget \& E. Thomas (Eds.), Adults in Higher Education: Learning from Experience in the New Europe (pp. 29-48). Acedido a 18/05/2010 em: http://books.google.com/books?id=DBmPFaGi5H8C\&printsec=frontcover\&dq=adults+in + higher+edu cation\&hl=pt-PT\&ei=72hETL-OItH84Abw6KGaDg\&sa=X\&oi=book_result\&ct=result\&resnum=1\&ved=

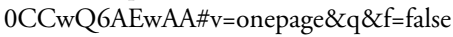

OECD (2007). Reviews of national policies for education - Tertiary education in Portugal. Paris: OECD Publications.

Pires, A. L. (2008). Aprendizagem de adultos: contextos e processos de desenvolvimento e reconhecimento de competências. Comunicação apresentada no Seminário Novos Públicos no IPS: os Maiores de 23 anos, Setúbal. Acedido a 16/02/2009 em: http://www.ips.pt/ips_si/web_gessi_docs.download_file?p_name=F446570191/ Aprendizagem_de_adultos.pdf

Pires, A. L. (2009). Reconhecimento e validação das aprendizagens não formais e informais no ensino superior. Problemas e perspectivas. Lisboa: Comunicação apresentada na Conferência Internacional sobre Creditação de Qualificaçōes não formais no Ensino Superior.

Schuetze, H. \& Slowey, M. (2002). Participation and exclusion: a comparative analysis of non-traditional students and lifelong learners in higher education. Higher Education, 44, 309-327. Acedido a 28/02/2010 em: http:// www.springerlink.com/content/u162346j8k6u5217/

Santiago, R., Rosa, M. J. \& Amaral, A. (2002). O Ensino Superior Aberto a Novos Públicos. Matosinhos: Centro de Investigaçáo de Políticas do Ensino Superior.

Silva, J. (2007). Relato da audiçẫo Novas Oportunidades para Novos Públicos no Ensino Superior. In P. Santos \& B. Campos (Coord.), Aprendizagem ao Longo da Vida no Debate Nacional sobre Educaşão. (pp. 121-124). Lisboa: Conselho Nacional de Educação.

UNESCO (2009). Comunicado da Conferência Mundial sobre Ensino Superior 2009. Comunicado da Conferência Mundial As Novas Mudanças do Ensino Superior e Pesquisas para a Mudança e o Desenvolvimento Social, Paris. Acedido a 2/08/2010 em: http://aplicweb.feevale.br/site/files/documentos/pdf/31442.pdf 
Série Documentos

Imprensa da Universidade de Coimbra

Coimbra University Press

2011

- U

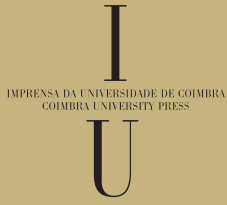

